Joana Figueiredo, Juan C. Moreno, Ana Catarina Matias, Fátima Pereira \& Cristina P. Santos (2019)

Outcome measures and motion capture systems for assessing lower limb orthosis-based interventions after stroke: a systematic review. Disability and Rehabilitation: Assistive Technology, DOI: 10.1080/17483107.2019.1695966

\title{
Outcome measures and motion capture systems for assessing lower limb orthosis-based interventions after stroke: A systematic review
}

Purpose: To review and categorize, according to the International Classification of Functioning, the outcome measures, and motion capture systems for studying the evidence-based practice of orthotic-based interventions in post-stroke gait rehabilitation.

Methods: An electronic literature search was conducted up to February 2018 in Web of Science, Scopus, MEDLINE, and Physiotherapy Evidence Database. Randomized trials measuring activity, impairment, or participation outcome measures for studying the evidence-based practice of orthoses in gait rehabilitation after an acute or chronic stroke were identified. The studies were assessed through the Cochrane risk-of-bias tool by three authors. Information about stroke's stage, assessment protocol (goal, timing, and motion capture system), orthosis configuration, and outcome measures were extracted.

Results: Eighteen randomized trials, including 387 post-stroke adults, mostly in the chronic stage, were selected. They assessed 39 outcomes, mainly activity outcome measures such as spatiotemporal (72.2\%), kinematic (44.4\%), and functional (33.3\%) outcomes. Gait speed was the primary outcome in most studies. Participation (22.2\%) and impairment (16.7\%) outcome measures were less explored. Mostly, non-portable motion capture systems were employed opposing the freely-use of the wearable orthosis. The detection bias risk and the shortage of baseline and follow-up outcome measures affected the studies' assessment quality.

Conclusions: Studies showed heterogeneity in selecting outcomes and timings for assessment. There is evidence for assessing the evidence of orthosis-based gait rehabilitation after stroke through activity outcome measures, primarily the gait speed, recorded by non-wearable motion capture systems. A unified methodology considering wearable sensors for tracking baseline and follow-up measures is needed.

Keywords: stroke; gait rehabilitation; wearable orthosis; outcome measures; gait assessment 


\section{Introduction}

The gait rehabilitation programs for a person who has a stroke are widely diverse. Particularly, wearable limb orthotic devices are becoming a prominent intervention for improving the functional ability of stroke victims by fostering a task-oriented and repetitive gait therapy [1]. The custom-made ankle-foot orthoses (AFOs), i.e., polypropylene leaf spring with a non-articulated joint [2,3], are the orthoses conventionally prescribed after a stroke [4,5]. Dynamic orthotic devices (made of carbonfiber) and knee orthosis are also used [6]. Powered wearable orthoses have also been investigated to foster a more accurate user-oriented assistance [7-9].

As with all available orthotic-based rehabilitation programs, regulatory and clinical decision-makers must weigh their benefits against their risks [10]. In this sense, the inclusion of outcome measures has gained importance through the years, driven primarily by the need for the evidence-based practice of the motor function to the acute and chronic stroke phases [10]. Quantifying the evaluation of the post-stroke motor function may involve the selection of outcome measures, standardized tools, instruments, or motion capture systems for assessing the treatment outcomes. Current directions also suggest that the integration of wearable motion capture systems in the orthotic-based interventions may enable the evaluation of the post-stroke functional ability in free-living environments [11-13].

The World Health Organization's International Classification of Functioning, Disability and Health (ICF: WHO, 2001, 2002) provides a multi-dimensional framework for health and disability. It identifies three categories of human functioning (body structure/impairment, activities, and participation/handicap), which are affected by environmental and personal factors. These categories can be used for classifying the outcome measures in post-stroke rehabilitation [14]. 
Diverse outcome measures have been explored in the post-stroke motor function assessment. A former review investigated the outcome measures used until 2000 in acute stroke trials, verifying that there was no consensus on the used outcomes (impairment measures, functional indicators, and quality of life measures), and the most appropriate timing for assessment [15]. Quinn et al. [16] observed heterogeneity in the use of functional outcome measures given the use of 47 functional metrics in 126 clinical trials of post-stroke rehabilitation. This study reported that the modified Rankin scale was the most prevalent outcome assessment [16]. The literature study conducted by Banks et al. [17] also observed that the modified Rankin scale is a valid and reliable measure for assessing post-stroke recovery. A more recent literature analysis identified a total of 34 outcome measures for assessing the upper and lower motor function in the chronic stroke phase, such as: Fugl-Meyer Upper Extremity and Lower Extremity scales, Wolf Motor Function Test, 10-m Walking Test (10MWT), 6-Minute Walking Test (6MWT), and the Stroke Impact Scale [10]. In this study, Fugl-Meyer Upper and Lower Extremity scales showing the strongest evidence for validity in chronic stroke populations [10]. Scrivener et al. [18] also verified a variability in outcome measures, including the Berg Balance Scale (BBS), various timed walking tests and the Rivermead Mobility Index, for quantifying the lower limb physical performance in the acute or subacute stroke phase. Furthermore, there have also been recent efforts to evaluate patients' satisfaction by using standardized, patient-reported outcome instruments, such as EQ-5D and the SF-36, focused on health-related quality of life measures [19,20].

Although numerous outcome measures for post-stroke motor function exist, as far as the authors know, it is not clear which most accurately measure meaningful change upon orthotic-based interventions. Additionally, the analysis of instruments and motion capture systems applied for measuring the outcome measures has not received attention. 
This systematic review aims to analyse the outcome measures applied in orthotic-based gait rehabilitation of post-stroke patients towards identifying the key outcomes, the most applied assessment instruments, and the most common timings for assessment. Moreover, this review investigates the relationship between the outcome measures and the used motion capture systems, the orthosis configuration and the stroke disease stage. Thus, the present literature review sought to answer the following research questions: (i) Which are the most measured outcomes in each ICF category?; (ii) Do the measured outcomes depend on the orthosis' configuration?; (iii) Are the motion capture systems wearable technologies?; (iv) Which is the most common timing for assessment?; and, (v) May the assessment protocol influence the quality of the outcome measures?. Lastly, this review presents recommendations to improve assessment practice since the clinical assessment protocol, and the outcome measures must be decided upon in advance.

\section{Methods}

\section{Search strategy}

A comprehensive literature search was conducted in February 2018 in Web of Science, Scopus, MEDLINE, and Physiotherapy Evidence Database. This electronic search involved the following keywords, combined with Boolean operators "AND", "NOT" and "OR": ["stroke"] AND ["lower limb orthosis" OR "ankle orthosis" OR "knee orthosis" OR "active orthosis" OR "powered orthosis"] AND ["rehabilitation" OR "assistance" OR "gait training"] AND ["outcomes" OR "gait measurements" OR "therapeutic scales" OR "clinical measures" OR "clinical scales" OR "assessment" OR "measures"] NOT ["functional electric stimulation"]. Wildcard symbols, such as hyphens or inverted commas, were used to consider all possible variations of root words. The search was 
limited to titles, keywords, and abstracts. All hits obtained with the search strategies were exported to Mendeley, where duplicates were removed.

\section{Studies selection}

The papers identified in this initial search were evaluated based on the following inclusion criteria: (i) presented an original research; (ii) included participants in an acute or chronic stage of stroke; (iii) investigated the outcome measures of the rehabilitation related to knee and/or ankle joint impairments; (iv) prescribed passive or active wearable lower limb orthoses; (v) measured objective or participation metrics to investigate the rehabilitation effects on locomotion; (vi) conducted clinical trials; and (vii) performed randomized controlled trials. No limitations to publication date were set. Articles were excluded if they: (i) were unpublished studies; (ii) used non-portable system associated with the orthotic device (e.g., Lokomat); (iii) used exoskeletons for the robotic gait training; (iv) employed orthoses with hip assistance; (v) involved healthy subjects or patients who exhibited gait impairments not caused by a stroke; (vi) prescribed other treatment approaches besides the orthotic therapy namely, functional electrical stimulation and brain computational interface.

The studies' selection followed the Preferred Reporting Items for Systematic Reviews and Meta-Analyzes (PRISMA) guidelines [21] to ensure the transparent and complete reporting of the results.

\section{Data extraction}

Two researchers (JF, AM) selected the studies and extracted the relevant data from them. Two independent researchers on the extraction process analysed and checked the extracted information (CS, JM, FP). Details of the assessment goal, post-stroke stage, orthosis prescribed, outcome measures, motion capture system, and timing for assessment 
(table 1), along with the total number of participants involved in the randomized trials and the sample size were extracted. The extracted information served as the benchmark for the discussion of the concepts of the issue in question.

\section{Methodologic quality assessment}

For each included study, three authors (JF, CS, AM) used the Cochrane risk-of-bias tool to assess the methodological quality in terms of sources bias regarding sequence generation, allocation concealment, blinding, incomplete outcome data, selective outcome reporting. For each one of these aspects, the studies were graded as an unclear, high, or low risk of bias. The total risk of bias was determined considering the assessments of each author to make an overall quality assessment of this review.

\section{Results}

\section{Studies selection and description}

Figure 1 presents the literature search process carried out in this review. A total of 229 citations were identified from all databases, and 56 studies were excluded after the removal of duplicates. The authors screened 173 abstracts and analysed 49 full-text articles. This review includes 18 studies, which met all the selected criteria.

Figure 1. Flow chart of literature search process.

The included trials involved 387 participants at different sample sizes, ranging from 3 [22] to 70 [23] participants. The sample sizes most observed (38.89\% of studies) range from 20 to 30 participants. Fifteen studies (83.33\%) included patients in the chronic stroke stage, whereas 6 studies (33.33\%) investigated the effects in the acute stage.

AFO was prescribed in 16 studies $(88.9 \%)$, while only 2 studies [22,24] used the knee orthosis. The conventional AFO configuration (i.e., polymeric, non-articulated 
posterior leaf-spring AFO) was applied in 15 randomized trials [5,23,33-37,25-32] whereas the studies $[33,38]$ used the anterior rigid configuration. Two studies $[35,37]$ explored a more compliant orthotic system by employing a dynamic AFO. From the fulltext article analysis, it was verified that the selected studies with active orthotic devices [7,8,39-43] did not accomplish randomized trials. As these studies did not meet the seventh eligibility criterium, they were not included in the systematic analysis.

\section{Methodological quality assessment}

The risk of bias was assessed in all included studies, as demonstrated in figure 2 and appendix. The generation of the allocation sequence was adequate in all included randomized trials since the studies conducted a random order of allocating the participants into interventions (100\% lower risk of bias). Additionally, allocation concealment was applied in most of the studies (94.44\%). Nevertheless, as depicted in figure 2 , the potential risk of bias concerning performance and detection was widely unclear. Sixteen studies $(88.9 \%)$ did not indicate if they applied strategies to blind study participants and personnel from the knowledge of which intervention a participant received. Similarly, 15 trials $(83.3 \%)$ did not provide any information relating to whether the blinding of outcome assessors was conducted or effective. Only 4 studies $(22.22 \%)$ clearly stated the application of blind of outcomes assessors.

The potential risk of bias likely to be introduced by incomplete data was mostly low ( $83.3 \%$ of a low risk of bias). Nonetheless, 5 trials $(27.8 \%)$ did not disclose complete data for part of the participants in the follow-up of or due to participants' withdrawals, leading to a $27.8 \%$ of the high risk of attrition bias. Moreover, low risk of selective reporting bias (100\%) was observed. This finding indicates that the reports of these trials are free of suggestion of selective outcome reporting by disclosing and investigating the pre-specified and expected outcomes. 
Figure 2. Analysis of risk of bias using Cochrane tool.

\section{Outcome measures for assessing post-stroke orthotic-based intervention}

Table 1 lists the information reviewed from 18 studies as well as the ICF category (body structure, activity, and participation) per outcome measure. Thirty-nine outcome measures were described in the included studies.

Table 1- Assessment protocol (goal, outcome measures, motion capture systems, and timing for assessment) in post-stroke orthotic-based rehabilitation. N/A means not available and $(*)$ indicates the primary outcome.

Findings presented in table 1 state that all studies used outcome measures (i.e., spatiotemporal, kinematic, kinetic, functional, and balance measures) into activity ICF category. Thirteen studies (72.2\%) investigated spatiotemporal metrics, which belong to activity category. Gait speed [23,24,26,30,32-36], step length [23,24,26,30,32-34,37], cadence [24,30,34,37], stride duration [24,32,33,36,37], and symmetry index [23,24,30] were the spatiotemporal parameters most recorded. The gait velocity was identified as the primary outcome $[23,24,28,30,34,36]$. Only one work reported the normalization of spatial metrics, namely the step length normalized to body height [34].

Eight studies (44.4\%) recorded kinematic metrics, including flexion/extension and range of motion (ROM) of hip and knee joints, dorsiflexion/plantarflexion and ROM of ankle joint [23,26,30,31,33-35,37]. Only 2 trials (11.1\%) studied kinetic indicators, such as the moment and force $[23,36]$.

Still approaching the activity category of ICF, 6 studies (33.3\%) assessed functional metrics (named as activity outcomes in ICF [14]). TUG, BBS scale, and 10MWT were the most measured functional metrics (in 6 and 5 studies, respectively). FAC, TUDS, and 6MWT were inspected in 3 studies. Nikamp et al. [28] also measured the Barthel index (BI) for assessing gait performance in daily activities. Moreover, 2 
studies (11.1\%) employed balance indicators, namely the weight-bearing asymmetry (assess the static balance control) [5] and postural stability [25].

A low percentage of trials $(16.7 \%)$ have analysed outcomes from the body function category. Three studies recorded the lower limb muscle activity of tibialis anterior [24,35,37], biceps femoris [37], and rectus femoris muscles [37].

Additionally, three studies measured body impairment outcome measures. These studies [23,33,38] assessed the spasticity level using the Modified Ashworth Scale (MAS). Two studies applied stroke-centered scales, namely the Modified Rivermead Mobility Index to evaluate the therapy effectiveness on mobility [23], and Brunnstrom scale to investigate the motor recovery [33].

Furthermore, 4 studies (22.2\%) measured participation outcomes into the participation category using satisfaction questionnaires [24], perceived exertion scale [29], and EuroQol EQ-5D-5L29 quality of life questionnaires [23,30]. Carse et al. [23] also performed interviews with the clinicians and patients before and after their participation in the study to evaluate the clinical potential of conventional AFO.

Non-portable motion capture systems were employed to measure the biomechanical parameters and balance metrics, which belong to the activity category. Infrared cameras, such as the Vicon system (Oxford Metrics, UK) and ELITE (BTS Bioengineering, Italy), were used to track spatiotemporal parameters and kinematic metrics. Four studies used force platforms, such as the AMTI BP400600 platform [30], GAITRite [32], Kistler platform (Switzerland) [34], pedar® platform [36], to measure the spatiotemporal outcomes. Cakar et al. [25] measured the postural stability with the Biodex system and a movable balance platform. Additionally, the body function outcomes, as the muscular activity, were recorded through electromyographic (EMG) 
systems, such as the EMG device from Zebris Medical GmbH [24], BTS FREEEMG [37], and Myopac EMG [35].

Six studies [22-24,28,30,31] presented baseline measures (namely spatiotemporal and kinematic outcomes) while 2 studies (11.1\%) investigated follow-up outcomes at 6 months [23] and 3 months [22]. Three studies [24,28,30] measured the baseline measures in the acute stroke phase, and the other 3 clinical trials $[22,23,31]$ involved participants with chronic hemiplegia.

All studies performed post-treatment assessments with variable timings for assessment (from 3 trials [33-35,37] to 35 months [5]). Seven studies (35\%) investigated more than one-month post-treatment assessments (1 month [24,32], 2 months [22], 4 months [28], 9 months [27], and 35 months [5]). The remaining works assessed the orthotic-based rehabilitation along consecutive trials $(3$ [33-35,37], $6[26,31]$ or 10 [36] trials). These 7 studies did not state the timings for assessment. The post-treatment assessment periods did not exceed 1 month (1 month [24,32], 7 days [30], and 3 trials $[33,35])$ for patients in the acute stage.

For participants in the acute stage, spatiotemporal metrics were measured in all studies [24,30,32,33,35], and kinematic metrics were considered in 3 trials $[30,33,35]$. Functional and balance metrics were less considered. In the chronic stage, the gait recovery was mostly inspected through spatiotemporal parameters $(38.9 \%$ of studies) $[23,26,31,32,34,36,37]$, kinematic measures $(27.8 \%$ of studies) $[23,26,31,34,37]$, and functional metrics $(22.2 \%$ of studies $)[5,27,29,38]$. Kinetic indicators were only applied for patients in the chronic stage $[23,36]$. Participation metrics and body impairment outcomes (MAS and Brunnstrom scale) were equally inspected in both the chronic and acute stages. 
Moreover, the review findings indicate that the activity category outcomes were recorded to investigate the gait recovery fostered by the conventional AFOs and knee orthoses [22,24]. Studies [35,37] compared the effects of dynamic AFOs to the conventional ones using outcomes belong to the body function category (muscular activity metrics) and activity category (temporal and kinematic indicators).

\section{Discussion}

This systematic analysis aims to support researchers and clinicians for studying the evidence-based practice of orthotic-based interventions in post-stroke gait rehabilitation. Overall, 39 outcome measures have been collected for assessing the orthosis-based gait rehabilitation in the chronic or acute stage. There is heterogeneity in the assessment protocol, namely in the selected outcome measures and timings for assessment, even when considering similar assessment goals. Previous systematic analyses $[15,16,44]$ also reported such heterogeneity.

\section{Most measured outcome measures according to ICF categories}

According to this systematic review, there is evidence for applying outcome measures from the activity category for assessing the orthosis-based gait rehabilitation. Most of the reviewed outcomes, such as biomechanical, functional, and balance outcomes, belong to the activity category. Additionally, this review demonstrated that the spatiotemporal measures were the most measured outcome measures [23,24,26,30,32-37]. Particularly, gait speed was pointed out as the primary outcome, given its contribution to measuring the increased motor function upon the orthotic-based intervention [30]. Lower limb kinematics were the second most measured outcomes [23,26,30,31,33-35,37], followed by functional metrics $[5,22,24,25,28,38]$. 
The prevalent use of activity outcome measures suggests that the evidence-based practice of the orthotic-based intervention primarily approaches the functional ability or difficulty that an individual might experience in completing a given motor activity [14].

So far, this is the first systematic review to focus on post-stroke gait assessment due to orthotic-based rehabilitation. Regardless of that, previous systematic analyses [1517,44] reported the use of activity outcome measures to assess the post-stroke gait recovery without involving orthotic devices. However, in such rehabilitation programs, functional outcome measures, such as the Modified Rankin Scale [16,17] and Fugl-Meyer scale [10], were reported as key measures.

On the other hand, the impairment and body function outcome measures, both belonging to the Body Structure ICF category, were the quantitative outcome measures less inspected to assess the orthotic-based rehabilitation in post-stroke survivors.

Few clinical trials investigated the applicability and usability of the orthotic-based gait rehabilitation for daily use through participation outcome measures [23,24,29,30]. A systematic review centered on assessing satisfaction with orthoses reported that objective measures continue to be more discerning than patient self-reports [19].

\section{Dependency on selected outcome measures to the orthosis' configuration}

Based on the performed analysis, there is not enough evidence to state a dependence between the selected outcome measures and the orthosis' configuration. This remark result from the different nature of outcome measures monitored in gait trials using the custom-made AFO configuration (more prescribed configuration). Nonetheless, there is a tendency to use balance and functional outcomes to explore the effectiveness of knee orthosis $[22,24]$. Gait speed was the key outcome to investigate the potential of dynamic devices when compared to the custom-made AFOs since there is evidence that the former configuration increases the walking speed in stroke subjects [45]. 


\section{Are the motion capture systems wearable technology?}

This review verified that the motion capture systems were only employed to record biomechanical and balance outcome measures and muscular activity. This body function outcome was measured using wearable EMG systems that can be easily worn by the users for the dynamic analysis of muscle activity [24,37].

In opposition, the studies used non-portable motion capture systems to monitor the activity outcome measures. These motion capture systems only operate in controlled environments [46] and are not able to analyse consecutive gait cycles in daily locomotion activities $[47,48]$. They cannot be worn by the users, in opposition to the prescribed orthoses. This finding may limit the potential added value of using wearable orthosis for gait training in daily locomotion activities.

\section{Most common timing for assessment}

There is not enough evidence to state which was the most used timing to assess the outcome measures upon orthotic-based gait training. This remark may be explained by the different assessment goals or by the inclusion of patients in the chronic and acute stages. Around one-third of the studies investigated more than one-month post-treatment assessments, whereas another third considered outcomes measured during a limited set of trials. Minor relevance was given to baseline and follow-up measures.

\section{Influence of the assessment protocol in the quality of outcome measures}

The risk of detection bias may influence the quality of the outcome measures since most studies $(83.3 \%)$ did not state whether the blinding of outcome assessors was conducted or effective. Unblinded outcome assessment can lead to biased conclusions of treatment effect [49]. The lack of blinded assessment was not associated with a particular outcome measure category. However, participation outcome measures may be more vulnerable to 
this bias. The high risk of attrition bias, observed in $27.8 \%$ of studies, may also affect the quality of the reported results due to the handling of incomplete outcomes.

Moreover, the representative absence ( $77.8 \%$ of the randomized trials) of baseline outcome measures may limit the assessment quality. This consideration would allow a clear standard for measuring the gait recovery upon the orthotic-based intervention by truly comparing the results pre- and post-treatment. Similarly, the completeness of assessments with follow-up measures would contribute to extending the representativeness of measured outcomes for long-term [50].

\section{Review limitations}

The limitations of this systematic review are mainly the considerable clinical diversity of the assessment protocols in the outcome measures and the timings for assessment. It was impossible to perform a meta-analysis given the sources of heterogeneity and the missing data in some studies.

The authors were exclusively responsible for developing selection criteria and screening the studies for inclusion. On the other hand, cross-checking may improve the quality of this review.

All included studies are randomised controlled trials; however, procedures for random selection are not described in most articles. Due to this criterion, trials with powered orthoses were not analysed, limiting the systematic analysis to passive devices.

Overall, reporting of various aspects of blinding techniques in open trials was poor. The main limitation of the generalizability of this review lies in the absence of information regarding the blinding of participants, personnel, and outcome assessors. Additionally, this review is limited by some risk of attrition bias in the included studies due to incomplete data reporting that may meaningfully affect the results. 


\section{Future directions}

Future directions to progress the evidence regarding orthotic-based rehabilitation in poststroke conditions are as follows. Future researches are recommended to approach a transparent declaration of blinded outcome assessment and to include baseline and follow-up outcomes to enable a critical appraisal of the orthoses' treatment effects. Moreover, it is necessary to describe the methodologies used to collect outcome measures using wearable systems. Furthermore, clinical studies involving active wearable orthotic systems must follow a randomized trial approach. The heterogeneity found in this analysis highlights the need for some agreement on assessing post-stroke rehabilitation towards a unified clinical methodology.

\section{Disclosure of interest}

The authors report no conflict of interest.

\section{References}

[1] Pennycott A, Wyss D, Vallery $\mathrm{H}$, et al. Towards more effective robotic gait training for stroke rehabilitation: a review. J. Neuroeng. Rehabil. 2012;9:65.

[2] Singer ML, Kobayashi T, Lincoln LS, et al. The effect of ankle-foot orthosis plantarflexion stiffness on ankle and knee joint kinematics and kinetics during first and second rockers of gait in individuals with stroke. Clin. Biomech. 2014;29:1077-1080.

[3] Ries AJ, Novacheck TF, Schwartz MH. The Efficacy of Ankle-Foot Orthoses on Improving the Gait of Children With Diplegic Cerebral Palsy: A Multiple Outcome Analysis. PM\&R. 2015;7:922-929.

[4] Olama KA, El-Din SMN, Ibrahem MB. Role of three side support ankle-foot orthosis in improving the balance in children with spastic diplegic cerebral palsy. 
Egypt. J. Med. Hum. Genet. 2012;14:77-85.

[5] Simons CDM, van Asseldonk EHF, Kooij H van der, et al. Ankle-foot orthoses in stroke: Effects on functional balance, weight-bearing asymmetry and the contribution of each lower limb to balance control. Clin. Biomech. 2009;24:769775.

[6] Boudarham J, Pradon D, Roche N, et al. Effects of a dynamic-ankle-foot orthosis (Liberté) on kinematics and electromyographic activity during gait in hemiplegic patients with spastic foot equinus. NeuroRehabilitation. 2014;35:369-379.

[7] Shihomi K, Koji O, Tadao T, et al. Development of new rehabilitation robot device that can be attached to the conventional Knee-Ankle-Foot-Orthosis for controlling the knee in individuals after stroke. IEEE Int. Conf. Rehabil. Robot. 2017;304307.

[8] Kim ES, Yoon YS, Sohn MK, et al. Effect of pneumatic compressing powered orthosis in stroke patients: Preliminary study. Ann. Rehabil. Med. 2015;39:226233.

[9] Tucker MR, Olivier J, Pagel A, et al. Control Strategies for Active Lower Extremity Prosthetics and Orthotics: A Review. J. Neuroeng. Rehabil. 2015;12:1.

[10] Bushnell C, Bettger J, Cockroft K, et al. Chronic Stroke Outcome Measures for Motor Function Intervention Trials: Expert Panel Recommendations. Circ Cardiovasc Qual Outcomes. 2017;8:1-13.

[11] Crea S, Donati M, De Rossi SMM, et al. A wireless flexible sensorized insole for gait analysis. Sensors. 2014;14:1073-1093.

[12] González I, Fontecha J, Hervás R, et al. An Ambulatory System for Gait Monitoring Based on Wireless Sensorized Insoles. Sensors. 2015;15:1658916613. 
[13] Lopez-Meyer P, Fulk GD, Sazonov ES. Automatic detection of temporal gait parameters in poststroke individuals. IEEE Trans. Inf. Technol. Biomed. 2011;15:594-601.

[14] Salter, Katherine; Campbell, Nerissa; Richardson, Marina; Mehta, Swati; Jutai, Jeffrey; Zettler, Laura; Moses, Matthew; McClure, Andrew; Mays, Rachel; Foley, Norine; Teasell R. Outcome measures in stroke rehabilitation. Evidence-Based Rev. Stroke Rehabil. 2013;110:1-144.

[15] Duncan PW, Jorgensen HS, Wade DT. Outcome measures in acute stroke trials: A systematic review and some recommendations to improve practice. Stroke. $2000 ; 31$

[16] Quinn TJ, Dawson J, Walters MR, et al. Functional outcome measures in contemporary stroke trials. Int. J. Stroke. 2009;4:200-205.

[17] Banks JL, Marotta CA. Outcomes validity and reliability of the modified rankin scale: Implications for stroke clinical trials - A literature review and synthesis. Stroke. 2007;38:1091-1096.

[18] Scrivener K, Sherrington C, Schurr K. A systematic review of the responsiveness of lower limb physical performance measures in inpatient care after stroke. BMC Neurol. 2013;13:0-7.

[19] Peaco A, Halsne E, Hafner BJ. Assessing Satisfaction With Orthotic Devices and Services: A Systematic Literature Review. JPO J. Prosthetics Orthot. 2011;23:95105.

[20] Velentgas P, Dreyer NA, Wu AW. Outcome Definition and Measurement. In: Quality A for H research and, editor. Dev. a Protoc. Obs. Comp. Eff. Res. A User's Guid. 2005. p. 71-90.

[21] Moher D, Liberati A, Tetzlaff J, et al. Preferred Reporting Items for Systematic 
Reviews and Meta-Analyses: The PRISMA Statement (Reprinted from Annals of Internal Medicine). Phys. Ther. 2009;89:873-880.

[22] Wong CK, Bishop L, Stein J. A wearable robotic knee orthosis for gait training: A case-series of hemiparetic stroke survivors. Prosthet. Orthot. Int. 2012;36:113120.

[23] Carse B, Bowers RJ, Meadows BC, et al. Visualisation to enhance biomechanical tuning of ankle-foot orthoses (AFOs) in stroke: study protocol for a randomised controlled trial. Trials. 2011;12:1-8.

[24] Portnoy S, Frechtel A, Raveh E, et al. Prevention of Genu Recurvatum in Poststroke Patients Using a Hinged Soft Knee Orthosis. PMR 2015;7:1042-1051.

[25] Cakar E, Durmus O, Tekin L, et al. The ankle-foot orthosis improves balance and reduces fall risk of chronic spastic hemiparetic patients. Eur. J. Phys. Rehabil. Med. 2010;46:363-368.

[26] Gatti MA, Freixes O, Fernández SA, et al. Effects of ankle foot orthosis in stiff knee gait in adults with hemiplegia. J. Biomech. 2012;45:2658-2661.

[27] de Wit DCM, Buurke JH, Nijlant JMM, et al. The effect of an ankle-foot orthosis on walking ability in chronic stroke patients: a randomized controlled trial. Clin. Rehabil. 2004;18:550-557.

[28] Nikamp CD, Buurke JH, van der Palen J, et al. Early or delayed provision of an ankle-foot orthosis in patients with acute and subacute stroke: A randomized controlled trial. Clin. Rehabil. 2016.

[29] Pavlik AJ. The effect of long-term ankle-foot orthosis use on gait in the poststroke population. J. Prosthetics Orthot. 2008;20:49-52.

[30] Carse B, Bowers R, Meadows BC, et al. The immediate effects of fitting and tuning solid ankle-foot orthoses in early stroke rehabilitation. Prosthet. Orthot. Int. 
2015;39(6):454-62.

[31] Zissimopoulos A, Fatone S, Gard S. Effects of ankle-foot orthoses on mediolateral foot-placement ability during post-stroke gait. Prosthet. Orthot. Int. 2015. Oct;39(5):372-9.

[32] Rao N, Chaudhuri G, Hasso D, et al. Gait assessment during the initial fitting of an ankle foot orthosis in individuals with stroke. Disabil. Rehabil. Assist. Technol.. 2008;3:201-207.

[33] Chen CCK, Hong WH, Wang CM, et al. Kinematic features of rear-foot motion using anterior and posterior ankle-foot orthoses in stroke patients with hemiplegic gait. Arch. Phys. Med. Rehabil. 2010;91:1862-1868.

[34] Farmani F, Mohseni-Bandpei MA, Bahramizadeh M, et al. The Influence of Rocker Bar Ankle Foot Orthosis on Gait in Patients with Chronic Hemiplegia. J. Stroke Cerebrovasc. Dis. 2016;25:2078-2082.

[35] Lairamore C, Garrison MK, Bandy W, et al. Comparison of tibialis anterior muscle electromyography, ankle angle, and velocity when individuals post stroke walk with different orthoses. Prosthet. Orthot. Int. 2011;35:402-410.

[36] Nolan KJ, Yarossi M. Preservation of the first rocker is related to increases in gait speed in individuals with hemiplegia and AFO. Clin. Biomech. 2011;26:655-660.

[37] Zollo L, Zaccheddu N, Ciancio AL, et al. Comparative analysis and quantitative evaluation of ankle-foot orthoses for foot drop in chronic hemiparetic patients. Eur. J. Phys. Rehabil. Med. 2015;51:185-196.

[38] Chen CL, Teng YL, Lou SZ, et al. Effects of an anterior ankle-foot orthosis on walking mobility in stroke patients: Get up and go and stair walking. Arch. Phys. Med. Rehabil. 2014;95:2167-2171.

[39] Blaya J a, Herr H. Adaptive control of a variable-impedance ankle-foot orthosis to 
assist drop-foot gait. IEEE Trans. Neural Syst. Rehabil. Eng. 2004;12:24-31.

[40] Kim J, Hwang S, Sohn R, et al. Development of an active ankle foot orthosis to prevent foot drop and toe drag in hemiplegic patients: A preliminary study. Appl. Bionics Biomech. 2011;8:377-384.

[41] Iida S, Kawakita D, Fujita T, et al. Exercise using a robotic knee orthosis in stroke patients with hemiplegia. J. Phys. Ther. Sci. 2017;1920-1924.

[42] Pourghasem A, Takamjani IE, Karimi MT, et al. The effect of a powered ankle foot orthosis on walking in a stroke subject: a case study. J. Phys. Ther. Sci. $2016 ; 28: 3236-3240$.

[43] Ward J, Sugar T, Boehler A, et al. Stroke survivors' gait adaptations to a powered ankle-foot orthosis. Adv. Robot. 2011;25:1879-1901.

[44] Geroin C, Mazzoleni S, Smania N, et al. Systematic review of outcome measures of walking training using electromechanical and robotic devices in patients with stroke. J. Rehabil. Med. 2013;45:987-996.

[45] Danielsson A, Sunnerhagen KS. Energy expenditure in stroke subjects walking with a carbon composite ankle foot orthosis. J. Rehabil. Med. 2004;36:165-168.

[46] Sabatini AM, Martelloni C, Scapellato S, et al. Assessment of walking features from foot inertial sensing. IEEE Trans. Biomed. Eng. 2005;52:486-494.

[47] Alahakone AU, Senanayake SMNA, Senanayake CM. Smart wearable device for real time gait event detection during running. IEEE Asia-Pacific Conf. Circuits Syst. Proceedings, APCCAS. 2010;612-615.

[48] Azhar MA, Gouwanda D, Gopalai AA. Development of an Intelligent Real - time Heuristic - based Algorithm to Identify Human Gait Events. 2014;573-576.

[49] Kahan BC, Rehal S, Cro S. Blinded outcome assessment was infrequently used and poorly reported in open trials. PLoS One. 2015;10:1-10. 
[50] Von Allmen RS, Weiss S, Tevaearai HT, et al. Completeness of follow-up determines validity of study findings: Results of a prospective repeated measures cohort study. PLoS One. 2015;10:1-13.

\section{Appendix}

Risk of bias assessment using Cochrane tool

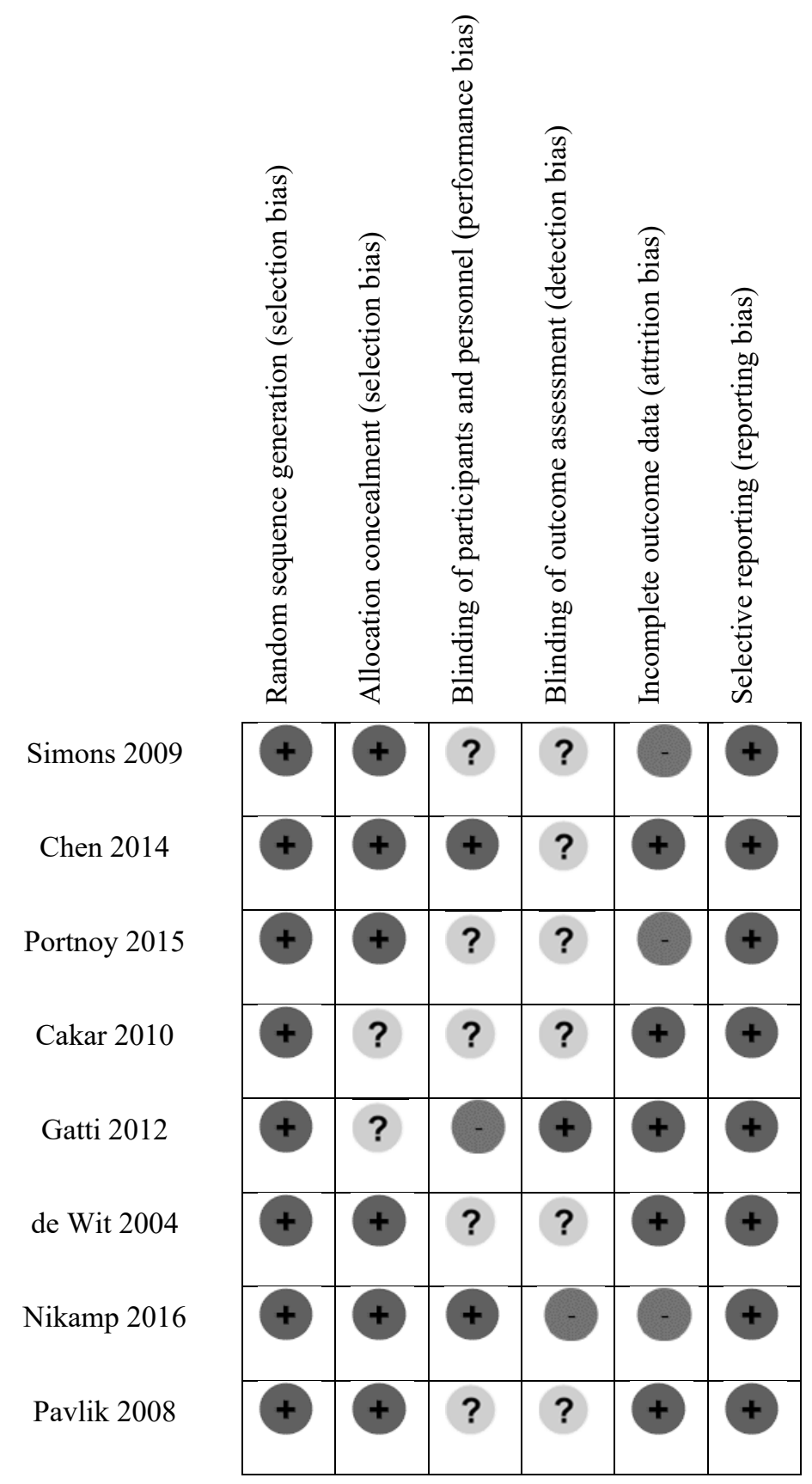




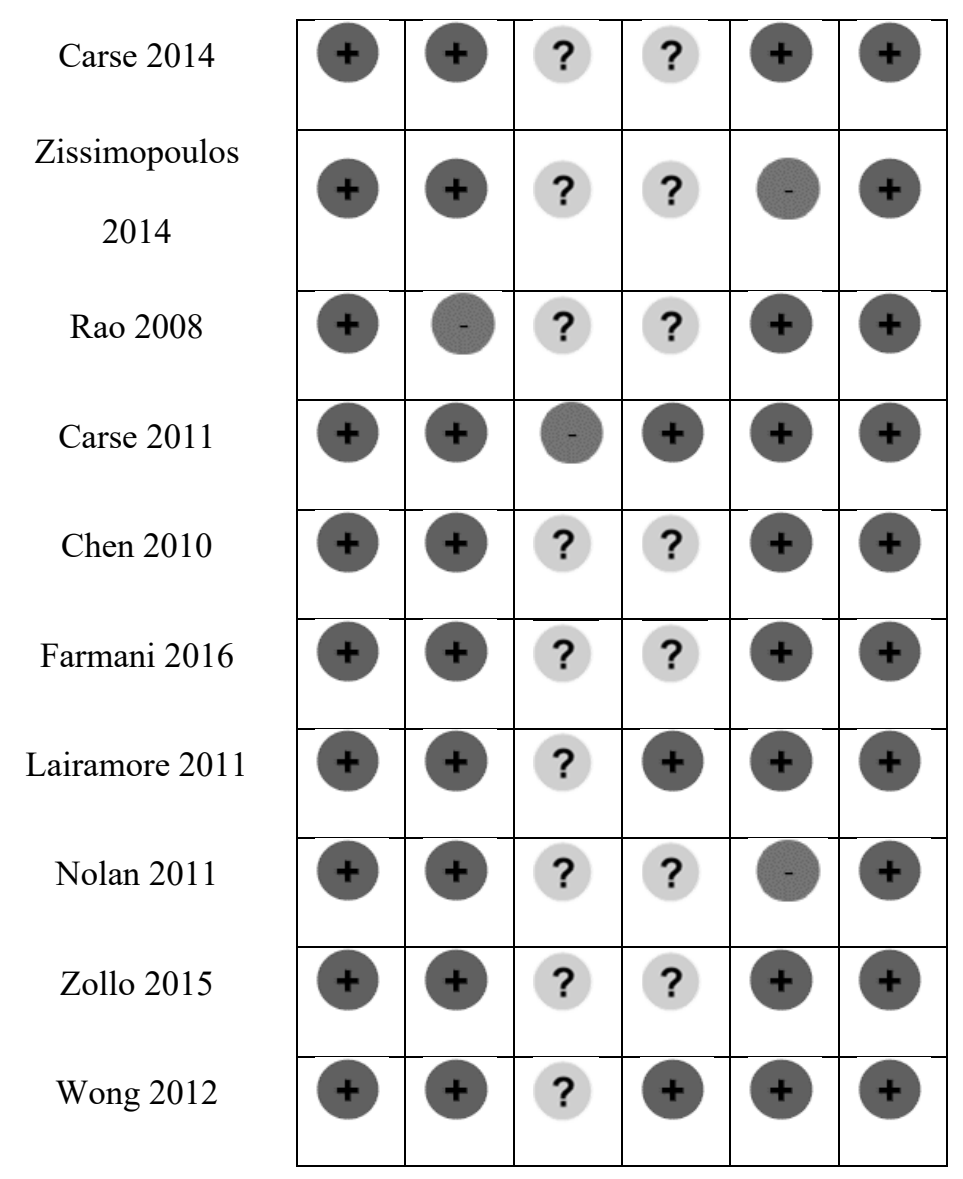

$+\quad$ Low risk of bias

? Unclear risk of bias

High risk of bias 
Table 1- Assessment protocol (goal, outcome measures, motion capture systems, and timing for assessment) in post-stroke orthotic-based rehabilitation. N/A means not available and $(*)$ indicates the primary outcome.

\begin{tabular}{|c|c|c|c|c|c|c|c|}
\hline \multirow[b]{2}{*}{ Study } & \multirow[b]{2}{*}{$\begin{array}{l}\text { Assessment } \\
\quad \text { goal }\end{array}$} & \multirow[b]{2}{*}{$\begin{array}{c}\text { Disease } \\
\text { stage }\end{array}$} & \multirow[b]{2}{*}{$\begin{array}{c}\text { Orthosis } \\
\text { configuration }\end{array}$} & \multicolumn{2}{|r|}{ Outcome measures } & \multirow[b]{2}{*}{ Motion capture system } & \multirow[b]{2}{*}{$\begin{array}{l}\text { Timing for } \\
\text { assessment }\end{array}$} \\
\hline & & & & $\begin{array}{c}\text { ICF } \\
\text { category }\end{array}$ & Description & & \\
\hline [5] & $\begin{array}{l}\text { Functional } \\
\text { and dynamic } \\
\text { balance }\end{array}$ & Chronic & $\begin{array}{l}\text { Conventional } \\
\mathrm{AFO} \text { and } \\
\text { metal AFO }\end{array}$ & Activity & $\begin{array}{l}\text {-Functional metrics: TUG, 10MWT, FAC, BBS. } \\
\text {-Balance metrics: Weight-bearing asymmetry, timed } \\
\text { balance test. }\end{array}$ & $\begin{array}{l}6 \text { DOFs motion platform } \\
\text { (MOTEK, Netherlands), } \\
\text { Vicon system (Vicon, UK) }\end{array}$ & $\begin{array}{l}\text { End of treatment: } \\
35 \text { months }\end{array}$ \\
\hline \multirow[t]{2}{*}{ [38] } & \multirow[t]{2}{*}{$\begin{array}{l}\text { Walking } \\
\text { ability }\end{array}$} & \multirow[t]{2}{*}{ Chronic } & \multirow[t]{2}{*}{ Anterior AFO } & $\begin{array}{l}\text { Body } \\
\text { impairment }\end{array}$ & -Impairment metrics: MAS. & \multirow[t]{2}{*}{$\mathrm{N} / \mathrm{A}$} & \multirow[t]{2}{*}{ N/A } \\
\hline & & & & Activity & -Functional metrics: TUG, TUDS, BBS. & & \\
\hline \multirow[t]{3}{*}{ [24] } & \multirow[t]{3}{*}{$\begin{array}{l}\text { Gait pattern } \\
\text { and symmetry }\end{array}$} & \multirow[t]{3}{*}{ Acute } & \multirow[t]{3}{*}{$\begin{array}{l}\text { Hinged knee } \\
\text { orthosis }\end{array}$} & $\begin{array}{l}\text { Body } \\
\text { function }\end{array}$ & -Muscle activity: electromyography. & \multirow{3}{*}{$\begin{array}{lrr}\text { 4-camera } & \text { system } & \text { (Basler } \\
\text { Scout, Basler } & \text { AG, } \\
\text { Germany), telemetric } \\
\text { EMG device } & \text { (Zebris } \\
\text { Medical } & \text { GmbH, } \\
\text { Germany) } & \end{array}$} & \multirow{3}{*}{$\begin{array}{l}\text {-Baseline; } \\
\text {-End of treatment: } \\
4 \text { weeks }\end{array}$} \\
\hline & & & & Activity & $\begin{array}{l}\text {-Spatiotemporal parameters: gait velocity, cadence, step } \\
\text { length, base width, stance, swing and double-support } \\
\text { duration, and symmetry index. } \\
\text {-Functional metrics: 6MWT, 10MWT }(*) \text {, TUG, BBS. }\end{array}$ & & \\
\hline & & & & Participation & $\begin{array}{l}\text { - Participation metrics: satisfaction questionnaire with } 9 \\
\text { questions concerned the orthotic fit, weight, durability, } \\
\text { appearance, the effect on clothes and skin, the difficulty } \\
\text { of donning, and related pain. }\end{array}$ & & \\
\hline [25] & $\begin{array}{l}\text { Balance and } \\
\text { fall risk } \\
\text { mitigation }\end{array}$ & Chronic & $\begin{array}{l}\text { Conventional } \\
\text { AFO }\end{array}$ & Activity & $\begin{array}{l}\text {-Functional metrics: BBS. } \\
\text {-Balance metric: postural stability measured by Biodex } \\
\text { system. }\end{array}$ & $\begin{array}{l}\text { Biodex System (USA), } \\
\text { movable balance platform }\end{array}$ & $\begin{array}{l}\text { End of treatment: } \\
1 \text { week }\end{array}$ \\
\hline [26] & $\begin{array}{l}\text { Knee joint } \\
\text { ability }\end{array}$ & Chronic & $\begin{array}{l}\text { Conventional } \\
\text { AFO }\end{array}$ & Activity & $\begin{array}{l}\text {-Spatiotemporal parameters: gait speed, step length. } \\
\text {-Kinematic metrics of paretic limb: knee flexion and } \\
\text { peak knee flexion angle. }\end{array}$ & $\begin{array}{lr}\text { ELITE } & \text { (BTS } \\
\text { Bioengineering, } \quad \text { Italy) } & \\
\text { with } 8 \text { infrared cameras }\end{array}$ & $\begin{array}{l}\text { End of treatment: } \\
6 \text { trials }\end{array}$ \\
\hline [27] & $\begin{array}{l}\text { Walking } \\
\text { ability }\end{array}$ & Chronic & $\begin{array}{l}\text { Conventional } \\
\mathrm{AFO}\end{array}$ & Activity & - Functional metrics: TUG, TUDS, FAC. & 2 infra-red beams & $\begin{array}{l}\text { End of treatment: } \\
9 \text { months }\end{array}$ \\
\hline [28] & $\begin{array}{l}\text { Balance and } \\
\text { walking } \\
\text { ability }\end{array}$ & Acute & $\begin{array}{l}\text { Conventional } \\
\text { AFO }\end{array}$ & Activity & $\begin{array}{l}\text {-Functional metrics: 10MWT }(*), 6 \mathrm{MWT} \text {, TUG, } \\
\text { TUDS, FAC, BI, BBS. }\end{array}$ & N/A & $\begin{array}{l}\text {-Baseline; } \\
\text {-End of treatment: } \\
2,9 \text { and } 11 \text { weeks }\end{array}$ \\
\hline \multirow[t]{2}{*}{ [29] } & \multirow{2}{*}{$\begin{array}{l}\text { Long-term } \\
\text { effect of } \\
\text { walking } \\
\text { ability }\end{array}$} & \multirow[t]{2}{*}{ Chronic } & \multirow{2}{*}{$\begin{array}{l}\text { Conventional } \\
\text { AFO }\end{array}$} & Activity & -Functional metrics: 10MWT, TUG. & \multirow[t]{2}{*}{ Footprints } & \multirow[t]{2}{*}{$\mathrm{N} / \mathrm{A}$} \\
\hline & & & & Participation & $\begin{array}{l}\text { - Participation metrics: perceived exertion scale (ranges } \\
\text { from } 6 \text { to } 20 \text { ) to assess the activity intensity of each trial } \\
\text { for each test. }\end{array}$ & & \\
\hline
\end{tabular}




\begin{tabular}{|c|c|c|c|c|c|c|c|}
\hline$[30]$ & $\begin{array}{l}\text { Immediate } \\
\text { biomechanical } \\
\text { ability }\end{array}$ & Acute & $\begin{array}{l}\text { Conventional } \\
\mathrm{AFO}\end{array}$ & Activity & $\begin{array}{l}\text {-Spatiotemporal parameters: walking velocity }(*) \text {, step } \\
\text { length symmetry ratio, average step length, cadence. } \\
\text {-Kinematics: thigh-to-vertical angle, shank-vertical } \\
\text { angle, maximum thigh-to-vertical angle of paretic } \\
\text { limb, knee flexion of paretic limb. }\end{array}$ & $\begin{array}{l}\text { 8-camera Vicon } 612 \\
\text { system (Oxford Metrics, } \\
\text { UK), } 2 \text { AMTI BP400600 } \\
\text { force platforms }\end{array}$ & $\begin{array}{l}\text {-Baseline; } \\
\text {-End of treatment: } \\
7 \text { days }\end{array}$ \\
\hline [31] & $\begin{array}{l}\text { Mediolateral } \\
\text { foot- } \\
\text { placement } \\
\text { ability }\end{array}$ & Chronic & $\begin{array}{l}\text { Non-rigid } \\
\text { AFO }\end{array}$ & Activity & $\begin{array}{l}\text { - Spatial metrics: mediolateral foot-placement between } \\
\text { the ankle and the target line }(0 \%, 15 \%, 30 \%, 45 \% \\
\text { subject's leg length) for each step; circumduction. } \\
\text { - Kinematic metrics: hip abduction/adduction angle, } \\
\text { peak pelvic angle. }\end{array}$ & $\begin{array}{l}\text { 8-camera digital motion } \\
\text { capture system }\end{array}$ & $\begin{array}{l}\text {-Baseline; } \\
\text {-End of treatment: } \\
6 \text { trials }\end{array}$ \\
\hline [32] & $\begin{array}{l}\text { Initial effects } \\
\text { on gait pattern }\end{array}$ & $\begin{array}{l}\text { Acute, } \\
\text { chronic }\end{array}$ & $\begin{array}{l}\text { Conventional } \\
\mathrm{AFO}\end{array}$ & Activity & $\begin{array}{l}\text {-Spatiotemporal parameters: gait speed; cadence; step } \\
\text { length of paretic and non-paretic limb; stance duration } \\
\text { of paretic and non-paretic limb }\end{array}$ & GAITRite1 system & $\begin{array}{l}\text { End of treatment: } \\
1 \text { month }\end{array}$ \\
\hline \multirow[t]{3}{*}{ [23] } & \multirow[t]{3}{*}{$\begin{array}{l}\text { Biomechanica } \\
1 \text { ability }\end{array}$} & \multirow[t]{3}{*}{ Chronic } & \multirow[t]{3}{*}{$\begin{array}{l}\text { Conventional } \\
\text { AFO }\end{array}$} & Activity & $\begin{array}{l}\text {-Spatiotemporal parameters: walking velocity }(*) \text {, step } \\
\text { length, symmetry ratio based on step length. } \\
\text {-Kinematic parameters: thigh and shank orientations. } \\
\text {-Kinetic indicators: knee and hip flexion/extension } \\
\text { moments. }\end{array}$ & \multirow[t]{3}{*}{ 3D motion analysis } & \multirow{3}{*}{$\begin{array}{l}\text {-Baseline } \\
\text { measures } \\
\text {-End of treatment } \\
3 \text { months } \\
\text {-Follow-up: } \\
\text { months }\end{array}$} \\
\hline & & & & $\begin{array}{l}\text { Body } \\
\text { impairment }\end{array}$ & $\begin{array}{l}\text { - Impairment metrics: MAS, Modified Rivermead } \\
\text { Mobility Index. }\end{array}$ & & \\
\hline & & & & Participation & $\begin{array}{l}\text { - Participation measures: EuroQol (EQ-5D); interviews } \\
\text { to the clinicians and patients before and after their } \\
\text { participation in the study. }\end{array}$ & & \\
\hline \multirow[t]{2}{*}{ [33] } & \multirow[t]{2}{*}{$\begin{array}{l}\text { Rear-foot } \\
\text { motion gait }\end{array}$} & \multirow[t]{2}{*}{ Acute } & \multirow{2}{*}{$\begin{array}{l}\text { Anterior and } \\
\text { posterior } \\
\text { AFOs }\end{array}$} & $\begin{array}{l}\text { Body } \\
\text { impairment }\end{array}$ & - Impairment metrics: Brunnstrom scale, MAS. & \multirow[t]{2}{*}{ Vicon system (Vicon, UK) } & \multirow[t]{2}{*}{$\begin{array}{l}\text { End of treatment: } \\
3 \text { trials }\end{array}$} \\
\hline & & & & Activity & $\begin{array}{l}\text {-Spatiotemporal parameters: walking speed, step length, } \\
\text { cycle time. } \\
\text {-Kinematic metrics: angles of the rear-foot joint in three } \\
\text { planes. }\end{array}$ & & \\
\hline [34] & $\begin{array}{l}\text { Biomechanica } \\
1 \text { ability }\end{array}$ & Chronic & $\begin{array}{l}\text { Conventional } \\
\text { AFO }\end{array}$ & Activity & $\begin{array}{l}\text {-Spatiotemporal parameters: step length normalized to } \\
\text { body height, cadence, gait velocity }(*) \text {, stance and pre- } \\
\text { swing time. } \\
\text {-Kinematic metrics: hip extension and knee flexion at } \\
\text { toe-off. }\end{array}$ & $\begin{array}{l}2 \text { force platforms (Kistler, } \\
\text { Switzerland), Vicon } \\
\text { system (Oxford Metrics, } \\
\text { UK) }\end{array}$ & $\begin{array}{l}\text { End of treatment: } \\
3 \text { trials }\end{array}$ \\
\hline \multirow[t]{2}{*}{ [35] } & \multirow{2}{*}{$\begin{array}{l}\text { Biomechanica } \\
1 \text { and muscular } \\
\text { ability }\end{array}$} & \multirow[t]{2}{*}{ Acute } & \multirow{2}{*}{$\begin{array}{l}\text { Conventional } \\
\text { AFO and } \\
\text { dynamic AFO }\end{array}$} & $\begin{array}{l}\text { Body } \\
\text { function }\end{array}$ & -Muscular activity: EMG from tibialis anterior muscle. & \multirow{2}{*}{$\begin{array}{l}\text { Myopac EMG unit } \\
\text { (Myopac), force plates, } \\
\text { Vicon System (Oxford } \\
\text { Metrics, UK) }\end{array}$} & \multirow[t]{2}{*}{$\begin{array}{l}\text { End of treatment: } \\
3 \text { trials }\end{array}$} \\
\hline & & & & Activity & -Temporal metric: gait velocity. & & \\
\hline
\end{tabular}




\begin{tabular}{|c|c|c|c|c|c|c|c|}
\hline & & & & & $\begin{array}{l}\text { - Kinematic metrics: ankle angle at initial contact and } \\
\text { mid-swing. }\end{array}$ & & \\
\hline [36] & $\begin{array}{l}\text { Double } \\
\text { support } \\
\text { changes } \\
\text { related to gait } \\
\text { speed }\end{array}$ & Chronic & $\begin{array}{l}\text { Conventional } \\
\text { AFO }\end{array}$ & Activity & $\begin{array}{l}\text {-Temporal metrics }(*) \text { : gait speed; duration of stride } \\
\text { initial double support, single support, and terminal } \\
\text { double support. } \\
\text {-Kinetic metrics }(*) \text { : mean force, and impulse } \\
\text { (bodyweight*seconds) in the wholefoot, hindfoot, } \\
\text { forefoot, and toe during initial double support. }\end{array}$ & 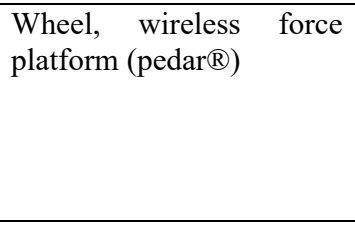 & $\begin{array}{l}\text { End of treatment: } \\
10 \text { trials }\end{array}$ \\
\hline \multirow[t]{2}{*}{ [37] } & \multirow[t]{2}{*}{$\begin{array}{l}\text { Biomechanica } \\
1 \text { and muscular } \\
\text { ability }\end{array}$} & \multirow[t]{2}{*}{ Chronic } & \multirow[t]{2}{*}{$\begin{array}{l}\text { Conventional } \\
\text { AFO and } \\
\text { dynamic AFO }\end{array}$} & $\begin{array}{l}\text { Body } \\
\text { function }\end{array}$ & $\begin{array}{l}\text {-Muscle activity: co-activation index of } \\
\text { gastrocnemius, tibialis anterior, biceps femoris, rectus } \\
\text { femoris muscles. }\end{array}$ & \multirow{2}{*}{$\begin{array}{l}\text { Stereo-photogrammetric } \\
\text { system (BTS Smart), } \\
\text { infrared cameras, } \\
\text { miniaturized EMG device } \\
\text { (BTS FREEEMG 300) }\end{array}$} & \multirow[t]{2}{*}{$\begin{array}{l}\text { End of treatment: } \\
3 \text { trials }\end{array}$} \\
\hline & & & & Activity & $\begin{array}{l}\text {-Spatiotemporal metrics: stride time, cadence, step } \\
\text { length, stride length, percentage of swing phase and } \\
\text { double stance phase; } \\
\text {-Kinematic metrics: angle at initial contact, ROM, } \\
\text { dorsiflexion peak during swing phase for ankle; knee } \\
\text { flexion/extension ROM; and flexion/extension ROM, } \\
\text { flexion peak during swing phase, and pelvic frontal } \\
\text { ROM for hip. }\end{array}$ & & \\
\hline$[22]$ & $\begin{array}{l}\text { Over-ground } \\
\text { balance and } \\
\text { walking } \\
\text { ability }\end{array}$ & Chronic & Knee orthosis & Activity & $\begin{array}{l}\text {-Functional metrics: 10MWT, 6MWT, BBS, five-time } \\
\text { sit-to-stand test (5TSST), and Emory Functional } \\
\text { Ambulation Profile (EFAP). }\end{array}$ & N/A & $\begin{array}{l}\text {-Baseline; End of } \\
\text { treatment: } 6 \\
\text { weeks; } \\
\text {-Follow-up: } \\
\text { 3months }\end{array}$ \\
\hline
\end{tabular}

